\title{
Public Safety Telecommunication Interoperability Two-way Radio Systems
}

\author{
Adil Akasha Mohammed ${ }^{1}$, Rashid Saeed ${ }^{2}$, Ala Eldin Awouda ${ }^{3}$ \\ Sudan university of science and technology Electronics Department, Sudan
}

*Corresponding Author: Adil Akasha Mohammed, Sudan University of science and technology Electronics Department, Sudan

\begin{abstract}
This paper reviews different wireless enterprise architecture standards to enable public safety voice communication interoperability using two-way radio. Different consoles and other means of third party between receiver and transmitter were used. The paper makes individual brief study to those solutions to compare between then, their optimal working areas and tabulates the results.
\end{abstract}

Keywords: public safety, interoperability, two-way radio.

\section{INTRODUCTION}

The services of the public safety organizations are important to the society by maintaining a stable and secure environment. These services provide protection to people from large number of natural and man-made threads. This includes acts of terrorism, technological, radiological or environmental accidents as illustrated in figure [1] [2], [3].

Information and Communication Technologies (ICT) have an important role in the public safety [3], [9]. The capability of exchanging information such as voice or data is essential to improve the coordination between public safety officers during an emergency. Additionally wireless communication is vital in field operations to support the mobility of first responders ${ }_{[2]}$.

One of the most challenges facing the public safety community today is the lack of communication interoperability, which is defined as "the ability of public safety emergency responders to communicate with whom they need to, when they need to, as authorized" [5],[7]. Communication interoperability serves as a tool for public safety and public service professionals, whether they are responding to a major incident, conducting a task force operation, or coordinating responses to daily events. This can provide life-saving support and can streamline response coordination efforts under circumstances, including incidents that employ emergency responders from multiple agencies or jurisdictions $_{[1]}$.

The challenge of communications interoperability for first responders was addressed in 1970 when the FIRESCOPE Incident Command System was developed in California as a result of a wild fire. The firefighting community realized that long term planning and coordination are essential to inter-agency communications. The public safety community is under pressure to meet immediate needs within their jurisdictions. To meet the demands of the present, it is challenging to plan for future and establish working plans to interoperate with neighbor communities [7], [3].

\section{TWO-WAY RADIO}

In a fields such as transportation, energy, government, retail, hospitality and many other industries, professional two-way radio systems offer capabilities that no other mobile technology can provide. Two-way radio system can offer professionals instant, private and cost-effective communication in any environment - anywhere and anytime ${ }_{[5]}$. There's no need to deploy supporting infrastructure in a field situation, or to rely on subscriber-based public networks that may be under-supported or

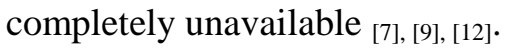

Two-way radio systems privately owned and operated wirelessly. Two-way radio is in fact the primary and preferred communications technology demanded by public and private organizations 
such as, business owners, manufacturing and industrial managers, transportation and logistics dispatchers, school and campus security personnel, Public Service, Emergency Management, and Homeland Security agency [5][6].

Two-way radio systems and wireless networks are time-tested, field-proven, highly effective, flexible, and versatile mobile communications' tools' offering numerous operational capabilities that can be easily customized for any type of application ${ }_{[8]}$.

Private radio/wireless systems are not subject to the same types of network accessibility risks, failures, air-time billing or service issues that public cellular subscriber-based systems are typically known for. Operational and management control of the systems remain with the equipment owner, system administrator, or service provider, who tend to be much more responsive and flexible when it comes to resolving any service issues than public carriers are ${ }_{[14]}$.

The cost of ownership and use', is significantly less on a long-term basis than is the monthly expense and other 'hidden' charges associated with the use of cellular, Nextel, paging, or other public systems [16].

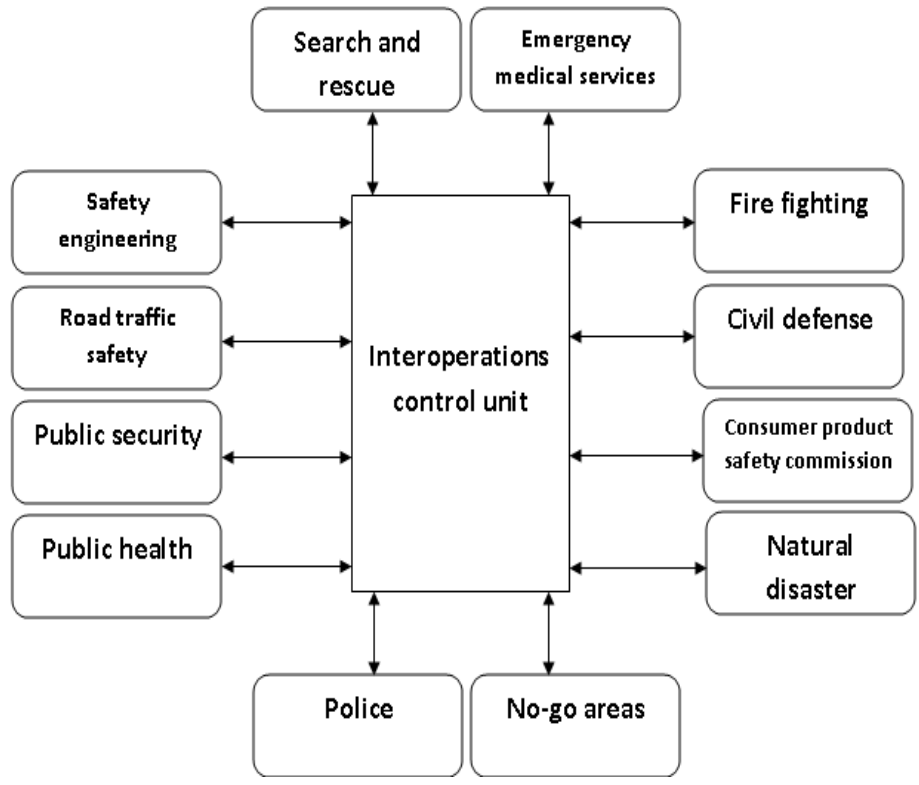

Fig1. Public Safety Organizations Samples [6]

A two-way radio is a radio that can both transmit and receive (a transceiver), allows the operator to have a conversation with other similar radios operating on the same radio frequency. The radios are available in mobile, stationary base and handheld portable configurations. They usually operate in a half-duplex mode; that is, the operator can talk, or listen, but not at the same time ${ }_{[8],[9]}$.

Two-way radios are classified into two types, the Conventional which operate on fixed RF channels such as Commercial and Public Safety Radio, marine VHF radio, family radio service (sometimes referred to by the abbreviation FRS), UNICOM and amateur radio ${ }_{[9]}$. And the trunked in which the system picks the radio frequency channel automatically. It uses a protocol that defines a relationship between the radios and the radio backbone which supports them. The protocol allows channel assignments to happen automatically $[7],[8]$.

Radios can be classified into groups which may be called, groups; talk groups, or divided into a hierarchy such as fleet and sub fleet, or agency-fleet-sub fleet ${ }_{[11]}$.

Systems make arrangements for handshaking and connections between classified radio groups by two methods one is a computer assigns channels over a control channel sends a continual data stream. All radios in the system receive the data stream until commanded by the computer to join a conversation on an assigned channel and the other is Electronics embedded in each radio communicate using a protocol of tones or data in order to establish a conversation, (scan-based) ${ }_{[8]}$.

Trunked radio types such as tetra, Logic Trunked Radio (abbreviated LTR), Smart Zone and Smart Net and EDACS $[7]$. 


\section{INTEROPERABILITY IN TWO-WAY RADIO SYSTEMS}

\subsection{The Coalition Peering Domain}

In this system the interoperation is not always direct, a network in- between is used .These terminals (responders) have no choice to select a connection because they are already build as fixed connections. The system is widely used in military as it can be considered as on agency [20], as shown in figure [2].

Coalition Member (CM) may be represented by either a single code, or a local network. Coalition members who have wide-area connectivity form the edge of the CPD and act as Coalition-Edge Forwarders (CEFs. In the simplest case they may forward outgoing packets on their CPD link. However, in a more interesting case they may forward some of these outgoing packets by distributing them, across the CPD edge, via their CPD-internal interfaces to other member CEFs within range, who then forward the packets outside the CPD. Thus outgoing traffic is distributed across multiple CEFs, which enables higher upstream data rate by multiple CM links. This type of wide-area connectivity is an example of collaboration between individuals for mutual benefit. This approach is useful when the local capacity between a number of CMs is greater than or equal to their individual capacity to a common remote entity .Coalition members without connectivity available to CPD, or who choose not to make available their wide area capability to other CMs, act as Coalition-Internal Forwarders (CIFs) ${ }_{[14]}$.

\subsection{Project 25 (P25)}

Association of Public Safety Communication Officials (APCO)1 Project 25 (P25) technology is a digital trunked radio system as shown in figure $\{3\}$ it provide both voice and low bandwidth data, and while primarily used by public safety agencies ${ }_{[13]}$.

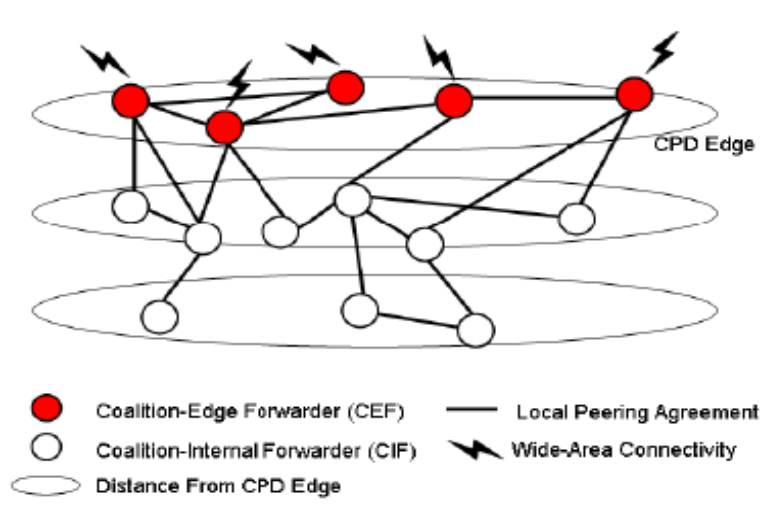

Fig2. CPD Architecture ${ }_{[14]}$

The system was developed based on emergency response professionals banding together and agencies interoperability. Its members include representatives from the Association of Public Safety Communications Officials International (APCO), the National Association of State Telecommunications Directors (NASTD), selected federal agencies and the National Communications System (NCS). These organizations formed a steering committee for selecting common system standards for public safety radio communications. The effort included a cooperation approach with the private sector to develop digital two-way radio systems that provided the functions needed by the public safety community $[18]$.

P25 phase I standards include digital Land Mobile Radio (LMR) services for local and state and federal public safety agencies. The use of P25 equipment is deployed separately in private system applications. P25 phase II involves time and frequency modulation schemes (e.g., TDMA and FDMA), with the goal of improved spectrum utilization. P25 also addresses interoperability with different radio systems equipments, repeaters and other subsystems, interfaces between repeaters, roaming capacity, other subsystems, channel reuse, and man-machine interfaces. On the other hand P25 phase III addresses the future of mobile high-speed data services for public-safety use. Phase III activities include a mobile wireless broadband public safety radio standard that support voice, video and high-speed data in a wide-area, multiple-agency two-way radio networks ${ }_{[19]}$. 


\subsection{Software Defined Radio (SDR)}

SDR is the next revolution in radio receiver technology. It contains efficient techniques for radio design of many advantages in terms of adaptability and re-configurability to support new waveforms and multi-functionality, such as bands, modes of operation, and air interfaces [26].

This technology depends upon obtaining communication parameters such as frequency band, type of modulation, data rate...etc. only by software ${ }_{[9]}$.

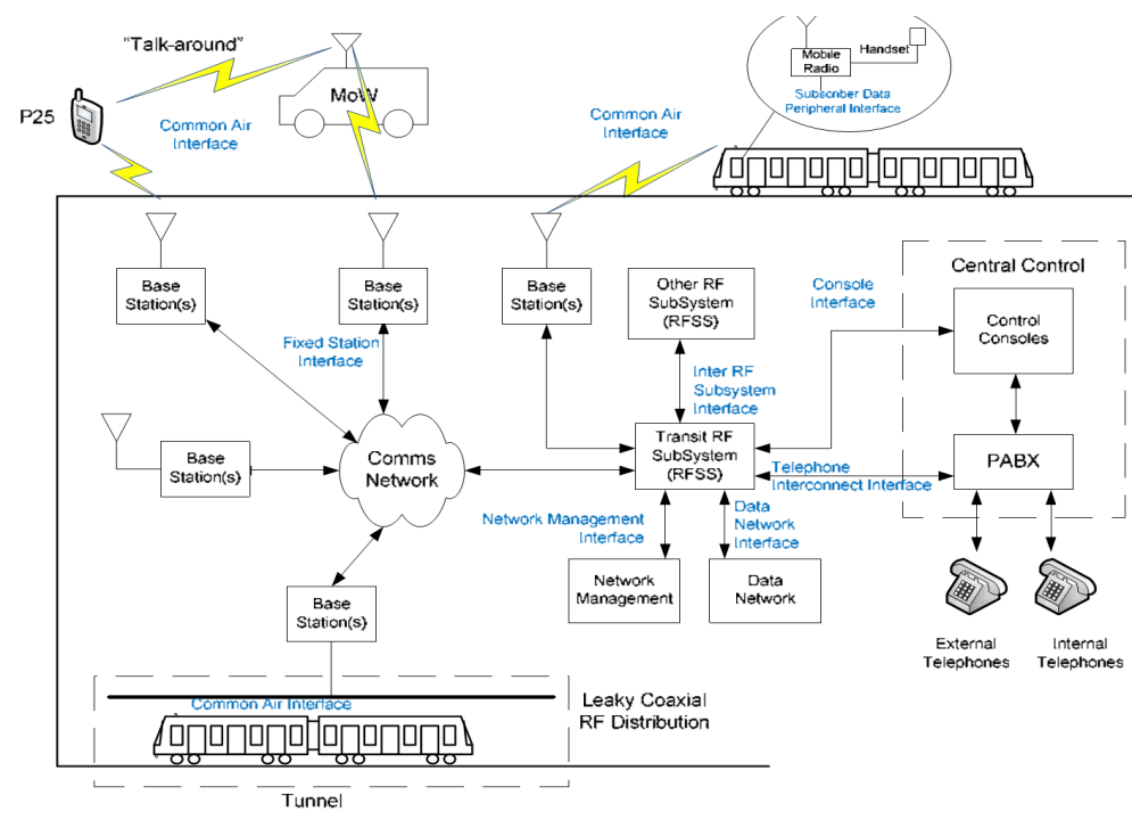

Fig3. APCO)1 Project 25 (P25) technology

Although this technology makes benefit for interoperability issues, but it joins radios, different bands, in one radio, SDR, rather than joining networks. Furthermore first responder may not be familiar with telecommunications terms [27], [27].

This type of interoperability is limited by the power amplifiers of the transmitter which cannot be programmed. Other drawbacks of this system is that, the user (responder) should be qualified enough and familiar with telecommunications terminologies. Furthermore, mobility is not supported, as in figure $[4]_{[6]}$.

The design tends to move from a hardware-centric design to a more flexible software-based design ${ }_{[8]}$.

\subsection{Wireless Gateways And Directional Antenna(WGDA)}

The gateways work as repeaters, receive a single frequency from responder and transmit in different bands, while the directional antenna point to the desired gateway depending upon the responder transmitted frequency ${ }_{[15],[16]}$, as shown in figure [5].

The antenna directivity is quite suitable for site communications, insures better communications performance.

Although the gateway design can be simple, but the directional antenna may include a very complicated control system.

The system is limited by the number of directions the antenna can be positioned ${ }_{[18]}$.

\subsection{Cellular and Internet $(\mathrm{CI})$}

Cellular and internet services offer data transfer in a higher speed than other radio network. However the existence of the third party limits the continuity and flexibility of the network.

Radio networks are preferable as private networks that are not affected by cellular or internet. Private networks choose the area of interest which may not be covered by cellular and internet ${ }_{[4]}$. 


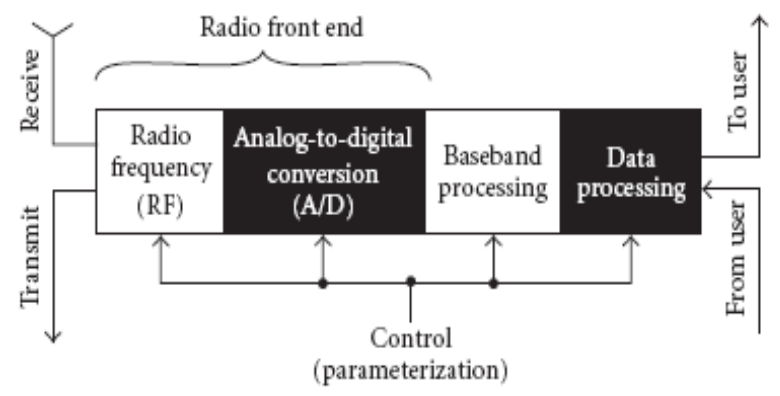

Fig4. SDR Architecture [6]

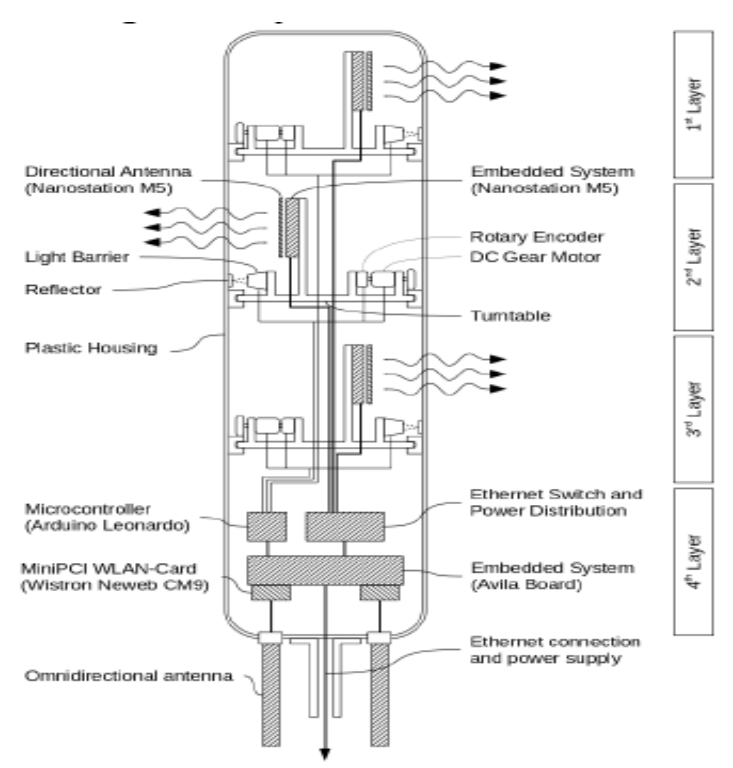

Fig5. Directional antenna

Advanced Control Unit (ACU)

Advanced Control Unit (ACU) is a large switching system which has an expanding capability to includes any number of networks, the connection between networks controlled by internal microprocessor which in turn controlled by user interface software, as shown in figure [6]. The manual operation of the ACU form a third party between first responder and the concerned agency, that makes the system with less benefits for time loss considerations [3].

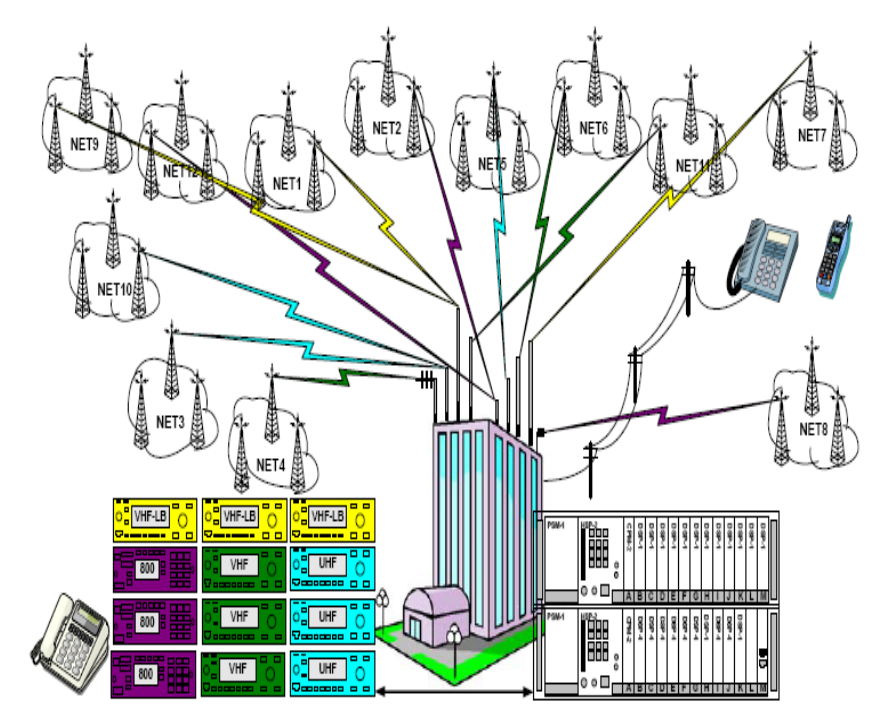

Fig6. ACU system Architecture [3] 


\section{COMMON DisadvantageS}

Individual municipalities have made their decisions regarding which radio system to purchase for many years. The end result, responders are not able to talk to each other because of incompatible equipment and/or different frequencies. Relevant and timely information is vital for tactical, strategic, and planning decisions when responding to emergencies. The large radio systems and equipment suppliers manufacture their own interoperability solutions which do not work with other manufacturer's radio equipment and are quite costly.

On the other hand the existence of the third party in the system such as internet, cellular or even a console in large two-way radio systems reduces the reliability of the whole design, increases the cost and lack of time.

\section{CONCLUSION}

Through the review of the various methods of public safety interoperability using two-way radio, a comparison table can be built to clearly explain that varieties and different application fields. The comparison of which is shown in table [1].

Table1. Comparison between different public safety two-way radio interoperability methods

\begin{tabular}{|c|c|c|c|c|c|}
\hline & $\begin{array}{c}\text { COVERAGE } \\
\text { AREA }\end{array}$ & $\begin{array}{c}\text { RELATIVE } \\
\text { No. OF } \\
\text { USERS }\end{array}$ & RELIABILITY & COMPLEXITY & $\begin{array}{c}\text { MAIN } \\
\text { DISAVANTAGE }\end{array}$ \\
\hline CPD & $\begin{array}{l}\text { Limited by the } \\
\text { network fixed } \\
\text { terminals }\end{array}$ & $\begin{array}{l}\text { Equal to No. of } \\
\text { terminals }\end{array}$ & $\begin{array}{c}\text { Less reliability } \\
\text { per single } \\
\text { connection }\end{array}$ & $\begin{array}{c}\text { Simple } \\
\text { connections }\end{array}$ & $\begin{array}{l}\text { Limited connection } \\
\text { paths }\end{array}$ \\
\hline $\mathbf{P 2 5}$ & $\begin{array}{c}\text { Can be expanded } \\
\text { relative to radio } \\
\text { type }\end{array}$ & $\begin{array}{l}\text { Up to the No. } \\
\text { of the radios }\end{array}$ & $\begin{array}{c}\text { Reliable per } \\
\text { single and group } \\
\text { connection }\end{array}$ & $\begin{array}{l}\text { Complicated } \\
\text { console }\end{array}$ & $\begin{array}{c}\text { Manual console } \\
\text { (lack of time) } \\
\text {.Needs } \\
\text { infrastructure }\end{array}$ \\
\hline SDR & $\begin{array}{c}\text { Can be expanded } \\
\text { relative to radio } \\
\text { type }\end{array}$ & $\begin{array}{l}\text { Up to the No. } \\
\text { of the radios }\end{array}$ & $\begin{array}{l}\text { Reliable per } \\
\text { single and group } \\
\text { connection }\end{array}$ & $\begin{array}{l}\text { Simple (single) } \\
\text { radio }\end{array}$ & $\begin{array}{l}\text { Type of frequency } \\
\text { sharing }\end{array}$ \\
\hline WGDA & $\begin{array}{l}\text { Limited by the } \\
\text { No. of directions } \\
\text { the antenna can } \\
\text { take }\end{array}$ & $\begin{array}{l}\text { Limited to } \\
\text { antenna } \\
\text { positions }\end{array}$ & $\begin{array}{l}\text { Not reliable } \\
\text { either per single } \\
\text { or group } \\
\text { connection }\end{array}$ & $\begin{array}{l}\text { Complicated } \\
\text { mechatronics }\end{array}$ & $\begin{array}{l}\text { Mechanical parts } \\
\text { sensitivity }\end{array}$ \\
\hline CI & $\begin{array}{l}\text { According to the } \\
\text { public network }\end{array}$ & $\begin{array}{l}\text { Limited to the } \\
\text { No. of } \\
\text { subscribers }\end{array}$ & $\begin{array}{c}\text { Reliable per } \\
\text { single and group } \\
\text { connection }\end{array}$ & Simple terminals & $\begin{array}{c}\text { Limited coverage } \\
\text { area }\end{array}$ \\
\hline $\mathbf{A C U}$ & $\begin{array}{c}\text { Can be expanded } \\
\text { relative to radio } \\
\text { type }\end{array}$ & $\begin{array}{l}\text { Up to the No. } \\
\text { of the radios }\end{array}$ & $\begin{array}{c}\text { Reliable per } \\
\text { single and group } \\
\text { connection }\end{array}$ & $\begin{array}{l}\text { Complicated } \\
\text { console }\end{array}$ & $\begin{array}{l}\text { Manual console } \\
\text { (lack of time) }\end{array}$ \\
\hline
\end{tabular}

\section{REFERENCES}

[1] Venkataraman, H., Sinanovic, S., \& Haas, H. (2008). Cluster-based design for two-hop cellular networks.International Journal for Communications, Networks and Systems (IJCNS), 1(4), 370-385

[2] Ikki, S. S., \& Ahmed, M. H. (2010). Performance analysis of best-path selection scheme for multi-hop amplify-and-forward relaying.European Transaction on Telecommunications,21(7), 603-610.

[3] Ann, S., \& Kim, H. S. (2010). Relay association method for optimal path in IEEE 802.16j mobile multihop relay networks.European Transaction on Telecommunications, 21(6), 624-631.

[4] Huang, J. H., Wang, L. C., Chang, C. J., \& Su, W. S. (2010). Design of optimum relay location in two-hop cellular systems.ACM/Springer Wireless Networks, 16(8), 2179-2189.

[5] Xie, R., Richard Yu, F., \& Ji, H., (2011). Joint power allocation and beamforming with users selec-tion for CR networks via discrete stochastic optimization.ACM Wireless Networks. doi:10.1007/s11276-0120413-8.

[6] Bian, K., \& Park, J. M. (2006). MAC-layer misbehaviours in multi-hop cognitive radio networks. In International conference on science, technology, and entrepreneurship (UKC), Korea, August 2006.

[7] Shin, J., Lee, D. K., \& Cho, H. S. (2009). Is a multi-hop relay scheme gainful in an IEEE 802.22-based cognitive radio system. 
[8] IEICE Transactions on Communications,92, 3528-3532.

[9] Zhuo Sun and Wenbo Wang "Investigation of Cooperation Technologies in Heterogeneous Wireless Networks", Journal of Computer Systems, Networks, and Communications, Volume (2010), Article ID 413987.

[10] Ermolov V. et al. "Significance of Nanotechnology for future wireless devices and Communications", The 18th Annual IEEE InternationalSymposium on PIMRC'07. International Journal of Next-Generation Networks (IJNGN) Vol.4, No.3,September 2012 .

[11] R.K.Jain, Risal Singh, "Role of Nanotechnology in future wireless and communication systems", National seminar proceeding, Academy of Business \& Engineering Science Ghaziabad, pp-19-28, 16-17th January 2009.

[12] Peter Mell and Timothy Grance, "The NIST Definitionof Cloud Computing" US National Institute of Standards and Technology Special Publication 800-145, September 2011.

[13] H. Zhang, Y. Zheng, M. A. Khojastepour, and S. Rangarajan, .Cross-Layer Optimization for Streaming Scalable Video over Fading Wireless Networks,. in IEEE JSAC, vol. 28, no. 3, April 2010

[14] Hulse, Jonathan, and Bowen Tritter. "Transit Agency Implementation of, or Migration to Digital Trunked Radio." 2013 Rail Conference .2013.

[15] Atkinson, Randall, et al. "A proposal for coalition networking in dynamic operational environments."Military Communications Conference, 2006. MILCOM 2006. IEEE. IEEE, 2006.

[16] De Sanctis, Mauro, et al."Interoperability solutions between smartphones and wireless sensor networks." 2012 IEEE first AESS European conference on satellite telecommunications (ESTEL) .2012.

[17] Dorfinger, P., et al. "Self-aligning wireless communication for first responder organizations in interoperable emergency scenarios." Proc. of the 2014International Conference on Wireless Networks (ICWN 2014) . 2014.

[18] Klein, David E., et al. "Enhanced public safety communication system." U.S. Patent No. 8,738,061. 27 May 2014.

[19] Nusev, Zoran, and Aleksandar Risteski. "Design Issues of Interoperable Communication System for Public Safety-Planning for the Unplanned." Computational Intelligence, Communication Systems and Networks (CICSyN), 2014 Sixth International Conference on. IEEE, 2014.

Citation: Adil Akasha Mohammed et al. (2017).Public Safety Telecommunication Interoperability Two-way Radio Systems, International Journal of Innovative Research in Electronics and Communications (IJIREC), 4(2), pp.26-32, DOI: http:// dx.doi.org/10.20431/2349-4050.0402005

Copyright: (C) 2017 Adil Akasha Mohammed et al. This is an open-access article distributed under the terms of the Creative Commons Attribution License, which permits unrestricted use, distribution, and reproduction in any medium, provided the original author and source are credited 